UCRL-ID-128999

\title{
Program for Certification of Waste from Contained Firing Facility - Establishment of Waste as Non-Reactive and Discussion of Potential Waste Generation Problems
}

\author{
LeRoy Green \\ Raul Garza \\ Jon Maienschein \\ César Pruneda
}

September 30, 1997

This is an informal report intended primarily for internal or limited external distribution. The opinions and conclusions stated are those of the author and may or may not be those of the Laboratory.

Work performed under the auspices of the U.S. Department of Energy by the Lawrence Livermore National Laboratory under Contract W-7405-Eng-48. 


\section{DISCLAIMER}

This document was prepared as an account of work sponsored by an agency of the United States Government. Neither the United States Government nor the University of California nor any of their employees, makes any warranty, express or implied, or assumes any legal liability or responsibility for the accuracy, completeness, or usefulness of any information, apparatus, product, or process disclosed, or represents that its use would not infringe privately owned rights. Reference herein to any specific commercial product, process, or service by trade name, trademark, manufacturer, or otherwise, does not necessarily constitute or imply its endorsement, recommendation, or favoring by the United States Government or the University of California. The views and opinions of authors expressed herein do not necessarily state or reflect those of the United States Government or the University of California, and shall not be used for advertising or product endorsement purposes.

This report has been reproduced directly from the best available copy.

Available to DOE and DOE contractors from the Office of Scientific and Technical Information

P.O. Box 62, Oak Ridge, TN 37831

Prices available from (615) 576-8401, FTS 626-8401

Available to the public from the

National Technical Information Service

U.S. Department of Commerce

5285 Port Royal Rd.,

Springfield, VA 22161 


\title{
Program for Certification of Waste \\ from Contained Firing Facility - Establishment of Waste as Non-Reactive and Discussion of Potential Waste Generation Problems
}

\author{
LeRoy Green, Raul Garza, Jon Maienschein, César Pruneda
}

September 30, 1997

\begin{abstract}
Debris from explosives testing in a shot tank that contains 4 weight percent or less of explosive is shown to be non-reactive under the specified testing protocol in the Code of Federal Regulations. This debris can then be regarded as a non-hazardous waste on the basis of reactivity, when collected and packaged in a specified manner. If it is contaminated with radioactive components (e.g. depleted uranium), it can therefore be disposed of as radioactive waste or mixed waste, as appropriate (note that debris may contain other materials that render it hazardous, such as beryllium). We also discuss potential waste generation issues in contained firing operations that are applicable to the planned new Contained Firing Facility (CFF).
\end{abstract}

\section{Scope of program and report}

The goal of this program is to develop and document conditions under which shot debris from the planned Contained Firing Facility (CFF) can be handled, shipped, and accepted for waste disposal as non-reactive radioactive or mixed waste.

This report fulfills the following requirements as established at the outset of the program:

1. Establish through testing the maximum level of explosive that can be in a waste and still have it certified as non-reactive.

2. Develop the procedure to confirm the acceptability of radioactivecontaminated debris as non-reactive waste at radioactive waste disposal sites.

3. Outline potential disposal protocols for different CFF scenarios (e.g. misfires with scattered explosive). 


\section{Introduction}

Shot debris from the Contained Firing Facility (CFF) may include radioactive components as well as unreacted explosives. Once depleted uranium is used in experiments at CFF, subsequent experiments will generate shot debris that will contain uranium at some level. This debris will presumably be considered low-level radioactive waste.

There is currently no disposal method for radioactive waste that is also classified reactive. Therefore, it is necessary that shot debris from the CFF can be packaged, shipped, and disposed of as non-reactive. This means that explosive constituents must be of a sufficiently low concentration that they pose no explosive hazard and are therefore non-reactive.

The goal of this program is to develop and document conditions under which shot debris from the Contained Firing Facility (CFF) can be accepted for waste disposal as non-reactive, radioactive waste.

\section{Establishment of maximum level of explosive in non-reactive waste}

3.1 Methodology for determination of the maximum level of explosive in non-reactive waste'

\subsubsection{Regulations defining reactive waste}

The characteristics that make a waste reactive are defined in the Code of Federal Regulations (CFR), Title 40 Section 261.23." The sections relevant to CFF waste state that "a solid waste exhibits the characteristic of reactivity if $\ldots$

(6) It is capable of detonation or explosive reaction if it is subjected to a strong initiating source or if heated under confinement.

(7) It is readily capable of detonation or explosive decomposition or reaction at standard temperature and pressure.

(8) It is a forbidden explosive as defined in 49 CFR 173.51, or a Class A explosive as defined in 49 CFR 173.53 or a Class B explosive as defined in 49 CFR 173.88."

We note that the terminology and section references in item (8) are obsolete. Forbidden explosives are now defined in 49 CFR 173.54. The designations "Class A explosive" and "Class B explosive" are no longer used; explosives are Class 1 materials, classified into 6 divisions, $1.1-1.6$, as defined in 49 CFR 173.50. Therefore, we restate the criteria in item (8) as "It is a forbidden explosive as defined in 49 CFR 173.54 (Forbidden Explosives) or a Class 1 explosive as defined in 49 CFR 173.57 (Acceptance criteria for new explosives) and 49 CFR 173.58 (Assignment of class and division for new explosives)."

\footnotetext{
- The Code of Federal Regulations version used here was revised as of July 1, 1996 for Title 40, and as of October 1, 1996 for Title 49.
} 
We also note that the criteria in items (6) and (7) of 40 CFR 261.23 are covered by the tests in 49 CFR 173.57 and definitions in 49 CFR 173.58. An item which shows reactivity under item (6) or (7) of 40 CFR 261.23 will also be defined as a Class 1 explosive and hence be deemed reactive by item (8) of 40 CFR 261.23. Therefore Items (6) and (7) are redundant, and need not be considered further.

The list of forbidden explosives in 49 CFR 173.54 lists specific explosive items, none of which are expected to be used at the CFF. Therefore, we have not considered forbidden explosives further in this program.

From the above excerpts of the CFR, and considering waste from the CFF, we therefore interpret the CFR sections cited above as follows: if a material is not a Class 1 explosive (49 CFR 173.57 and 49 CFR 173.58), then it is not a reactive waste (40 CFR 261.23). This is the criterion used in this project to qualify waste containing a low concentration of explosives as non-reactive.

The protocol for determining whether a material is a Class 1 explosive is defined by the United Nations, ${ }^{1}$ as specified in 49 CFR 173.57. The protocol, as detailed in a series of flowcharts (Figures 10.1, 10.2, and 10.3 in Reference 1), requires a set of tests identified as Series 3 and Series 6 . These tests address the reactivity of the material by itself, and as packaged for shipment. If a material shows no hazardous nature in these tests (as defined below), then it is qualified as not Class 1, and hence for our purposes not reactive."

\subsubsection{Tests to determine Class 1 explosives}

Series 3 tests are comprised of small-scale tests on the material: (a) impact sensitivity by drop hammer; (b) friction by BAM tester; (c) thermal stability at $75^{\circ} \mathrm{C}$; and (d) small-scale burning test. Series 6 tests includes a set of tests of the material packaged for shipment: (a) explosive initiation test of one package to see if deliberate stimulation by a detonator will set off an energetic reaction; (b) explosive initiation test of a stack of packages to see if reactions propagate from one package to the next; and (c) thermal test to see if exposure to a fire will set off an energetic reaction. If the Series 6(a) test shows that there is no damage to the exterior of the package, then the Series 6(b) test is waived. ${ }^{1}$

It was not necessary to conduct Series 6 tests on all explosives. We instead used the explosive most sensitive to initiation that we typically handle,

- There is ambiguity in the United Nations protocol. If the material in question was "manufactured with the view to producing a practical explosive or pyrotechnic effect," then the Series 3 and Series 6 tests are required. If not, a simpler Series 1 set of tests is required. We took the conservative approach that the waste must pass the more stringent Series 3 and Series 6 tests, although the waste was not "manufactured with the view to producing a practical explosive or pyrotechnic effect." This approach was required by the U.S. Department of Transportation for LLNL-developed explosive simulants and was adopted here as well. 
PETN, for the Series 6 tests, and established a level that is non-reactive. Since our other explosives are less-easily initiated by a detonator or fire, they will pass the Series 6 tests when at the same level for which PETN is non-reactive, and they may therefore be certified by analogy as non-reactive in the Series 6 tests." The Series 3 tests, however, must be performed for each explosive mixed with clay at an explosive level of at least 4 weight percent. (The debris from the explosives tests must not include materials that would increase the sensitivity to initiation and make it reactive at the $4 \%$ explosives level).

Details of the Series 3 and Series 6 tests are given in Appendices A and B.

\subsubsection{Composition of surrogate waste used in this program}

The components of the surrogate waste that we tested were defined by the expected operations of the CFF. If fine particles or explosive dust remain in the firing chamber after an incomplete explosive reaction (visible pieces of explosives having been collected and removed or detonated), then the shot debris will be collected using a clay floor sweeping compound as a normal part of the cleanup process. Therefore, we selected the clay used for floor sweeping as the major component of our surrogate waste material. We tested this clay with the different explosives anticipated to be used in the CFF.

\subsubsection{Configuration of waste packaging}

The Series 6 tests involve the material packaged for shipment. The configuration used in these tests was a $9 \mathrm{~kg}(20 \mathrm{lb}$.) mass of the surrogate waste contained in a plastic bag; the bag was placed in the center of a UNIA2 55-gallon drum equipped with a carbon filter, with a layer of clay surrounding it and occupying the remainder of the volume as dunnage. This dunnage is about 8 inches thick on the sides, and about 14 inches thick on top and bottom. Therefore the results in this report are applicable only to waste containing mostly clay floor sweeping compound packaged in this configuration. Different inert components or different packaging configurations are not considered here, and must be evaluated at the time such changes are made.

\subsection{Results - level of explosives that may be present in non-reactive waste}

A list of the explosives considered in this report, and the relevant data for each, is shown in Appendix C.

A mixture of 4 weight percent PETN in clay passes the Series 6 tests. Therefore, by analogy a mixture of any explosive (as long as it is

- This certification by analogy was accepted by the U.S. Department of Transportation for LLNL-developed explosive simulants. 
acknowledged less sensitive than PETN, e.g. not a primary explosive such as lead azide or mercury fulminate) in clay containing 4 weight percent or less of explosive will pass the Series 6 tests.

The complete set of Series 3 tests have been conducted for the explosives shown in Appendix C. All of the explosives tested passed the Series 3 tests at a 4 weight percent or greater concentration.

Therefore, any waste composed primarily of floor-sweep clay that contains 4 weight percent or less of explosives listed in Appendix $\mathrm{C}$ is non-reactive, as defined by the CFR and the United Nations protocol.

\section{Determination of explosive content of waste from CFF}

From the results of the previous section, debris from the CFF must be certified as containing less than 4 weight percent of explosive in order to be certified as non-reactive. We identify several methods by which this can be accomplished.

The first and probably most desirable is a simple accounting of the mass of unrecovered explosive that is in the debris. In the event of an unsuccessful detonation or incomplete explosive reaction, there will likely be sizable pieces of explosive that can be picked up and recovered. The mass of explosive in the original assembly will be known; subtracting the mass of explosive recovered from the initial explosive mass gives the mass of explosive that is presumed to be in the debris (this is conservative, ignoring the probable consumption of some of the explosive in the test). From this mass of explosive and the mass of debris and clay floor sweep required to clean up the shot tank, the mass concentration of explosive can be calculated. As long as this is less than or equal to 4 weight percent, the waste is non-reactive."

A second method to establish the concentration of explosive in debris is through Differential Scanning Calorimetry (DSC) analysis. In DSC, a small sample of waste is heated while the energy released from energetic reactions is measured. The amount of energy released is an indication of the quantity of explosive present in the sample. The DSC technique is implemented with commercial equipment which use small samples (several milligrams). Each explosive responds quantitatively differently in the DSC. Therefore, two conditions must be met to use DSC to quantify explosive concentration. First, the identity of the explosive must be known. Second, a calibration curve for the DSC of energy release as a function of concentration of that explosive must be measured for known mixtures of the explosive and clay. We also note that care must be taken when sampling debris and clay floor sweep mixture to obtain a representative sample.

\footnotetext{
- This assumes that the waste is well mixed, with any explosive uniformly distributed throughout the debris and clay. Care must be taken during the cleanup operation to ensure that the debris is well mixed with the floor sweep.
} 
A third method to establish the concentration of explosive in debris is chemical analysis, possibly preceded by chemical extraction to concentrate the explosive residue that was present in the debris. This is a more complex task than either of the above methods, but provides the opportunity to sample large masses of debris, reducing the challenge of obtaining a representative sample in a few milligrams of material.

\section{Acceptability of CFF waste for disposal}

Waste from the CFF must be collected and packaged as specified in section 3.1. It must be comprised primarily of debris and clay floor sweeping compound, and it must be shown to contain less than 4 weight percent explosive to be declared non-reactive. Furthermore, it must be packaged in $9 \mathrm{~kg}(20 \mathrm{lb}$.) or less quantities, with each $9 \mathrm{~kg}$ lot in a separate UNIA2 55gallon drum equipped with a carbon filter. The waste must be in a plastic bag in the center of the drum, with more clean clay occupying the remainder of the drum volume.

Under the above limitations, the waste is qualified by the information in this report as non-reactive. It can therefore be disposed of as radioactive or mixed waste, as required by the presence of other components, and disposal can occur by normal means.

\section{Potential disposal protocols for different CFF scenarios}

There are a number of potential incidents associated with the confined firing chamber operations that could become sources of explosive (i.e. reactive) hazardous waste. These are listed and discussed below:

1. A misfire or experiment in the chamber that scatters explosive is a potential source of reactive waste.

All explosives scattered by a misfire or experiment that can be recovered must be picked up and destroyed in place or recovered for later use." It is necessary that the weight of all explosives in an experiment be known, so that when recoverable explosive is weighed, the weight of any explosive remaining in the chamber will be known.

2. The debris and residue left after most of the scattered explosive has been picked up by hand is another potential source of explosive waste.

Explosive left in the firing chamber after removal of all recoverable explosive is to be removed from the chamber

\footnotetext{
- Under the provisions of the recently-enacted Military Munitions Rule by the EPA, Range Clearance Operations will allow the detonation of unexploded explosive that remains after a test. ${ }^{2}$
} 
by the use of a clay sweeping compound (kitty litter) and a broom. One must know the maximum possible weight of explosive residue that may be left in the chamber. Then, by knowing the weight of sweeping compound required to clean the chamber, one can reasonably estimate the concentration of explosive in the sweeping compound/debris mixture. Alternatively, DSC analysis can be used to measure the concentration of explosive in the waste. As long as the concentration is equal or less than 4 weight percent (see test results section of report), the mixture will be a non-reactive waste.

The amount of clay floor sweeping compound that is required for a cleanup operation must be determined in advance, to avoid the appearance of debris treatment by dilution with clay to achieve an explosives concentration of less than 4 weight percent. The specific amount of clay to be used will be determined by the CFF operations staff as they gain experience with cleaning the firing chamber.

3. Unexploded explosive from misfires or experiments that ends up in the filters for the wash water after the chamber is washed down is a potential source of reactive waste.

If all scattered explosive is picked up properly and the chamber is cleaned properly with the sweeping compound prior to wash down, then residue from the filters will be quite low in explosive content and most likely be of sufficiently low percentage of explosive as to not constitute reactive hazardous waste. It is very important that these steps just outlined be followed. A DSC measurement should be made of filter residue after any experiment that results in scattered explosives; in this way one can verify that the residue contains less than 4 weight percent explosive, using the worst-case calibration curve, i.e. the curve that gives the highest level of explosive concentration for the energy release. Alternatively, chemical analysis can be used.

4. Explosive that ends up in solution in the wash water is a potential source of reactive waste. An explosive with high solubility in water could result in creation of waste water contaminated with explosives as well as radioactive materials.

The solubility of virtually all common explosives in water is so low that this is not a concern. If an explosive has a high solubility in water, then the use of that explosive in the contained firing chamber must be 
carefully controlled. The amount of explosive that could possibly end up in the wash water would have to be monitored by tracking explosive masses, and a chemical analysis would probably be required to establish the level of explosive.

\section{Conclusions}

Shot debris from the Contained Firing Facility will likely contain radioactive contaminants, and therefore must be non-reactive for disposal. If scattered explosives have been collected and destroyed or recovered, and the remaining material is cleaned up with clay floor sweep, the resulting waste will be non-reactive as long as the explosive concentration is 4 weight percent or less. The level of explosive concentration may be established by tracking the mass of explosives used and recovered, by Differential Scanning Calorimetry, or by chemical analysis.

Several possible scenarios for generation of explosive waste are discussed, along with methods to prevent their generation.

\section{Acknowledgments}

We thanks Chet Lee and Jeff Wardell for their excellent support of the experimental work. Tests were conducted in HEAF and at Site 300 Bunker 812 , and the respective operations crews were very helpful and instrumental in successful completion of the tests.

\section{References}

1. Recommendations on the Transport of Dangerous Goods. Manual of Tests and Criteria, Second Revised Edition, ST/SG/AC.10/11/Rev.2, United Nations, New York (1995).

2. R.P. Guarienti, LLNL, Briefing at Site 300 on Military Munitions Rule, March 17, 1997. 


\section{Appendix A. Description of Series 3 tests}

Series 3 tests are comprised of four small-scale tests on the material: (a) impact sensitivity by drop hammer; (b) friction by BAM tester; (c) thermal stability at $75^{\circ} \mathrm{C}$; and (d) small-scale burning test. ${ }^{A-1}$

Test 3(a) is the impact sensitivity test; the purpose is to measure the sensitivity of the material to an impact from a dropped weight. A $2.5 \mathrm{~kg}$ weight is dropped onto $35 \mathrm{mg}$ samples of the material from different heights and any reaction is detected. The reported value is the height in centimeters at which $50 \%$ of the drops result in a reaction. The test is documented further in Reference A-2. Typical heights for standard explosives are shown in Table A-1. If the 50\%-go drop height is greater than that of dry RDX, the test result is negative and the material remains a candidate as a non-reactive material. If the 50\%-go drop height is less than or equal to that of dry RDX, the test result is positive and the material is considered reactive.

Table A-1. Typical results from the LLNL Drop Hammer Impact Sensitivity Test

\begin{tabular}{|c|c|}
\hline Explosive & Drop Hammer Result, cm \\
\hline PETN " & $15 \pm 3$ \\
\hline RDX & $37 \pm 6$ \\
\hline HMX & $31 \pm 4$ \\
\hline Comp B-3 & $50 \pm 4$ \\
\hline TNT & $61 \pm 9$ \\
\hline TATB & $>177$ \\
\hline
\end{tabular}

Test 3(b) is the friction sensitivity test; the purpose is to measure the sensitivity of the material to frictional stimuli. A standard friction testing machine, the BAM machine, is specified by the UN and is used at LLNL. In this instrument, the material is rubbed between a rounded rod and a coarse porcelain plate while under load. An explosive reaction, as evidenced by loud report, crackling, spark, or flame) indicates a positive response at that load. The final reported value is the load or force needed to give one reaction in ten tests. Typical loads for standard explosives are shown in Table A-2. The test is documented further in Reference A-3. If the load to give 1 reaction in 10 tests is greater or equal to $80 \mathrm{~N}$, the test result is negative and the material remains a candidate as a non-reactive material. If the load to give 1 reaction in 10 tests is less than $80 \mathrm{~N}$, the test result is positive and the material is considered reactive. 
Table A-2. Typical results from the LLNL Friction Sensitivity (BAM) Test

\begin{tabular}{|c|c|}
\hline Fxplosive & Load to give 1 reaction in 10 tests \\
\hline PETN & $60 \mathrm{~N}$ \\
\hline RDX & $120 \mathrm{~N}$ \\
\hline HMX & $120 \mathrm{~N}$ \\
\hline LX-17 (TATB/Kel-F) & $>360 \mathrm{~N}$ \\
\hline
\end{tabular}

Test 3(c) is the thermal stability test at $75^{\circ} \mathrm{C}$; the purpose is to measure the stability of the material when subjected to elevated temperatures. There are two versions of this test, uninstrumented and instrumented. If a material is thermally stable in the uninstrumented test, the instrumented test is not required; the instrumented test may be run in place of the uninstrumented test if desired. If in the test(s) the material is thermally stable, it remains a candidate as a non-reactive material. A material that is not thermally stable is considered reactive.

In the uninstrumented test, a 50 gram sample is placed in a beaker, covered, and held in an oven at $75^{\circ} \mathrm{C}$ for 48 hours or until reaction or explosion takes place, if sooner). If there is no ignition or explosion, and no evidence of thermal instability (i.e. fuming, decomposition, significant mass loss), the material is considered thermally stable.

In the instrumented test, a 100-gram sample is placed in a container. An inert sample of equal mass is placed in a second identical container. Both containers are placed in an oven at $75^{\circ} \mathrm{C}$ and held for 48 hours (or until reaction or explosion takes place, if sooner). The temperatures of both containers are monitored during this time, to allow measurement of any exothermic reaction and resultant selfheating in the sample. At the end of the test, the sample is inspected for any sign of reaction. If there is no ignition or explosion and no significant self-heating, the material is considered thermally stable.

Test 3(d) is the small-scale burning test; the purpose is to determine the response of the material to a fire. A 125-gram sample is placed on top of kerosene-soaked sawdust, which is then ignited. The fire is observed visually. The test must be conducted in triplicate. If the material does not burn, or simply burns along with the kerosene-sawdust, it passes this test and remains a candidate as non-reactive material. If it explodes, it is considered reactive. ${ }^{\Psi}$

\footnotetext{
${ }^{\Psi}$ In the previous revision of Reference 1 (Rev. 1), Test 3(d) was defined to be run with 125 grams of material, in triplicate. In the current revision of Reference 1 (Rev. 2), Test 3(d) is defined as two runs with 10 grams of material and two runs with 100 grams. Our tests followed the specifications in Rev.1, which are in any case more stringent than those in Rev.2.
} 


\section{References}

A-1. Recommendations on the Transport of Dangerous Goods. Manual of Tests and Criteria, Second Revised Edition, ST/SG/AC.10/11/Rev.2, United Nations, New York (1995).

A-2. L.R. Simpson, M.F. Foltz, "LLNL Small-Scale Drop-Hammer Impact Sensitivity Test," UCRL-ID-119665, Lawrence Livermore National Laboratory (January 1995).

A-3. L.R. Simpson, M.F. Foltz, "LLNL Small-Scale Friction Sensitivity (BAM) Test," UCRL-ID-124563, Lawrence Livermore National Laboratory (June 1996). 


\section{Appendix B. Description of Series 6 tests}

Series 6 tests are designed to test the material in the configuration in which it will be shipped. The tests measure the response of the packaged material to an internal explosion and to an external fire. ${ }^{\mathrm{B}-1}$

Test 6(a) measures the response of the packaged material to an internal explosion. A standard detonator (defined in Reference B-1) is placed near the center of the packaged material and fired. The material is classified depending on the severity of the ensuing reaction. If there is no reaction, the material remains a candidate as a non-reactive material. Triplicate testing is required.

Test 6(b) is like Test 6(a), but with several packages of the material. The purpose is to measure the propagation of reaction from one container to another. If Test 6(a) shows no external damage to the package, then Test $6(\mathrm{~b})$ is waived.

Test 6(c) measures the response of the packaged material to an external fire. Three packages of the material are placed as close together as possible, and subjected to an external fire. The fire must be hot enough and of sufficient duration to consume all the explosive. The classification of the material depends on the severity of the response, ranging from mass explosion of the package to no hazardous effects at all. If there are no hazardous effects, the material remains a candidate as a non-reactive material.

For all Series 6 tests, the material was packaged in a UNIA2 55-gallon shipping container that is qualified as a low-level radioactive waste shipping container. The drum lid was equipped with a carbon filter to allow air to move in and out of the drum due to temperature changes; this is the shipping configuration for this type of waste.

\section{References}

B-1. Recommendations on the Transport of Dangerous Goods. Manual of Tests and Criteria, Second Revised Edition, ST/SG/AC.10/11/Rev.2, United Nations, New York (1995). 
Appendix C. Results of test for explosives considered likely to be used in the Contained Firing Facility firing chamber

Table C-1 lists the explosives covered in this program.

The major explosive constituents considered are PETN, HMX, RDX, TATB, CL-20, and TNT. We tested each of these pure explosives, diluted with clay, to establish that the diluted pure explosives are non-reactive in the Series 3 tests. We tested pure PETN diluted with clay to establish that diluted pure PETN is non-reactive in the Series 6 test. Since all the other listed explosives are less sensitive to heat and shock than PETN, the others pass the Series 6 test by analogy.

For explosives formulated from one of above constituents and an unreactive binder such as Viton A, Kel-F 800, or Estane, the formulated explosive will be less reactive than the pure constituent. Therefore, the data for the pure constituent are sufficient to qualify debris containing the formulation as well as the pure constituent. These explosive formulations are listed in Table C-1, with data shown only for the pure constituent.

For explosives formulated with an energetic liquid, binder, or plasticizer, the formulated explosive may be more or less reactive than the pure constituent. Therefore, the actual formulation must be tested in the Series 3 protocol. Formulations for which this has been done are listed in Table C-1. Others not listed must be tested in order to qualify the debris as nonreactive.

Comments on the Series 3 and Series 6 tests are included below. More detail is given in a separate report (Reference $\mathrm{C}-1$ ).

\section{Series 3(a) - Impact sensitivity}

For many explosives, the 50\%-no go height for the pure explosive is greater than that of RDX. Therefore the pure explosive passes the test and the explosive mixed with 96 weight percent clay can be deemed to pass the test without actual testing. For explosives with a 50\%-no go height less than RDX, the mixture of clay and explosive must be tested. The results are shown in Table C-1.

\section{Series 3(b) - Friction sensitivity}

For many explosives, the load for 1 response in 10 tests for the pure explosive is greater than or equal to $80 \mathrm{~N}$. Therefore the pure explosive passes the test and the explosive mixed with 96 weight percent clay can be deemed to pass the test without actual testing. For explosives with the load for 1 response in 10 tests less than $80 \mathrm{~N}$, the mixture of clay and explosive must be tested. The results are shown in Table C-1. 
Table C-1. Series 3 Test Results*

\begin{tabular}{|c|c|c|c|c|}
\hline Explosive & $\begin{array}{c}\text { 3(a) Impact } \\
\text { sensitivity } \\
\text { result, cm } \\
\text { (>37 = pass) }\end{array}$ & $\begin{array}{c}\text { 3(b) Friction } \\
\text { sensitivity } \\
\text { result, N } \\
(>80=\text { pass) }\end{array}$ & $\begin{array}{c}\text { 3(c) Thermal } \\
\text { stability } \\
\text { result }\end{array}$ & $\begin{array}{c}\text { 3(d) Small- } \\
\text { scale } \\
\text { burning } \\
\text { result }\end{array}$ \\
\hline $\begin{array}{c}\text { PETN } \\
\text { LX-16 }\end{array}$ & $>177(11 \%)$ & $>360(11 \%)$ & pass (4\%) & pass (4\%) \\
\hline $\begin{array}{c}\text { HMX } \\
\text { LX-04 } \\
\text { LX-07 } \\
\text { LX-10 } \\
\text { LX-11 } \\
\text { LX-14 }\end{array}$ & $168(15 \%)$ & $120(100 \%)$ & pass (15\%) & pass (15\%) \\
\hline PBX-9404 & $168(15 \%)$ & $250(100 \%)$ & pass (15\%) & pass (15\%) \\
\hline PBX-9501 & $>177(15 \%)$ & $360(15 \%)$ & pass (15\%) & pass (15\%) \\
\hline $\begin{array}{c}\text { RX-08-HD } \\
\text { RDX } \\
\text { PBX-9407 }\end{array}$ & $>168(15 \%)$ & $190(100 \%)$ & pass (15\%) & pass (15\%) \\
\hline $\begin{array}{c}\text { TATB } \\
\text { LX-17 } \\
\text { PBX-9502 }\end{array}$ & $>177(100 \%)$ & $120(100 \%)$ & pass (15\%) & pass (15\%) \\
\hline $\begin{array}{c}\text { CL-20 } \\
\text { LX-19 }\end{array}$ & $161(15 \%)$ & $>360(100 \%)$ & pass (15\%) & pass (15\%) \\
\hline TNT & $>177(15 \%)$ & $360(100 \%)$ & pass (15\%) & pass (15\%) \\
\hline
\end{tabular}

*Data are listed for pure PETN, HMX, RDX, TATB, CL-20, and TNT mixed with clay, showing that these pure explosives are non-reactive when diluted by clay (weight percent explosive in the explosive/clay sample is shown in parentheses, all are greater than or equal to 4 weight percent). Formulations with these constituents and an unreactive binder are listed along with the pure constituents - these do not require separate testing, since the formulations are less reactive than the pure constituent. Formulations that include other energetic component are listed separately, since they may be more or less reactive than the pure constituent.

\section{Series 3(c) - Thermal stability}

We have conducted the thermal stability test on all pure constituents and formulations with energetic components, and all passed. This is shown in Table C-1. We have also made standard LLNL Chemical Reactivity Test (CRT) $^{\mathrm{C}-2}$ measurements on the materials, and they have passed this test. This test is more stringent than the Series 3(c) test, and offers an additional level of confidence in the thermal stability of these materials. 


\section{Series 3(d) - Small-scale burning}

We have conducted the small scale burning test on all pure constituents and formulations with energetic components, and all passed. This is shown in Table C-1.

\section{Series 6(a) - Initiation test}

As explained in the main text, we ran the 6(a) test only on mixtures of PETN and clay. Since this explosive is more sensitive than the others listed in Table C-1, we qualify the others by analogy as having passed this test. Surrogate waste containing 4 weight percent PETN was packaged as described in Section 3.1.4, above. We tested three drums containing the surrogate waste. The 6(a) protocol calls for testing with a standard detonator containing 0.6 grams of PETN. We tested with SE-1 detonators containing 0.6 grams of PETN. We also subjected each drum to a significant overtest by adding a booster pellet, weighing 1.2 gram, of RX-26AF (46.6\% TATB, 49.3\% HMX, 4.1\% Estane). In all tests with the detonator alone and with the detonator plus booster pellet, the mixture of 4 weight percent PETN / 96 weight percent clay showed no sign of reaction, with the drum exterior being undisturbed and the internal contents merely showing the effect of the detonator or detonator/booster combination. Therefore, this mixture passes the 6(a) initiation test. Figures C-1 and C-2 below show the three barrels before and after the test with detonator and booster.

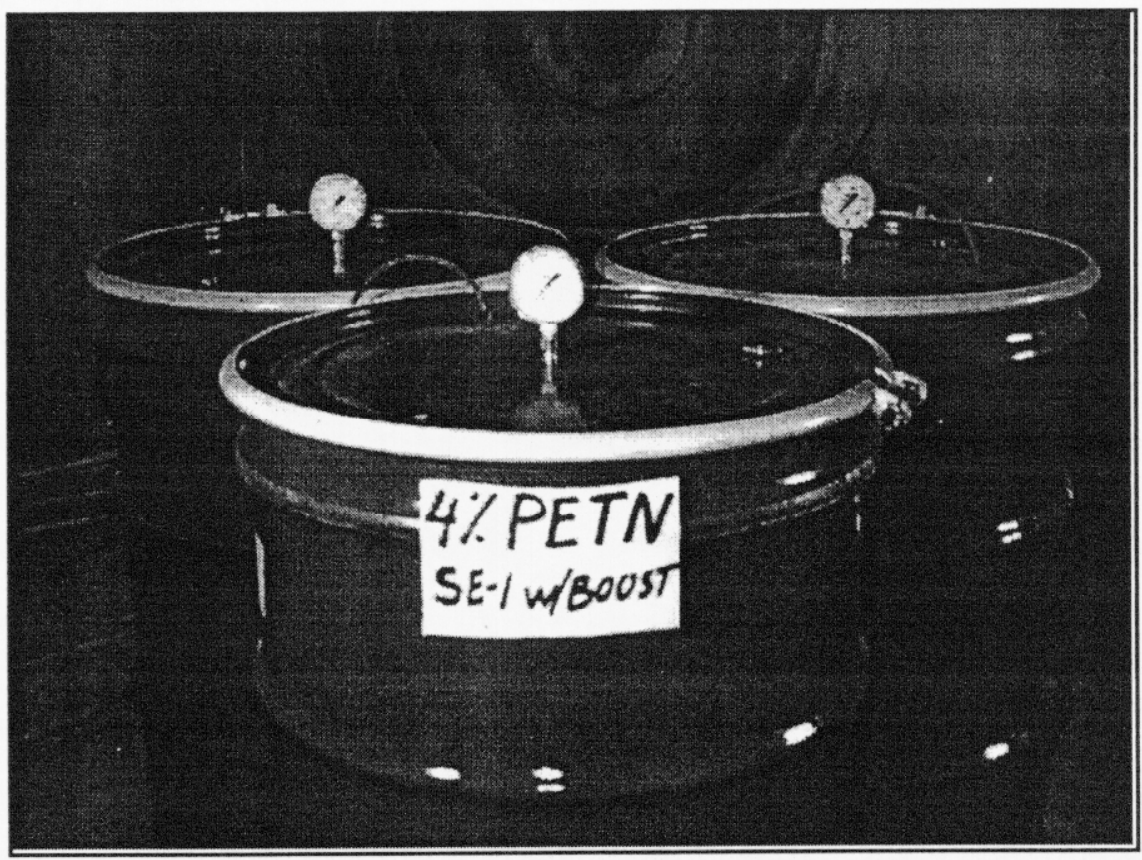

Figure C-1. Three barrels containing 4 weight percent PETN in clay, in the firing tank for the Series 6(a) test. Pressure gauge mounted on each barrel monitored for pressure increase from burning PETN that was ignited by the detonator / booster pellet. No such pressure increases were observed, showing that no ignition occurred. 


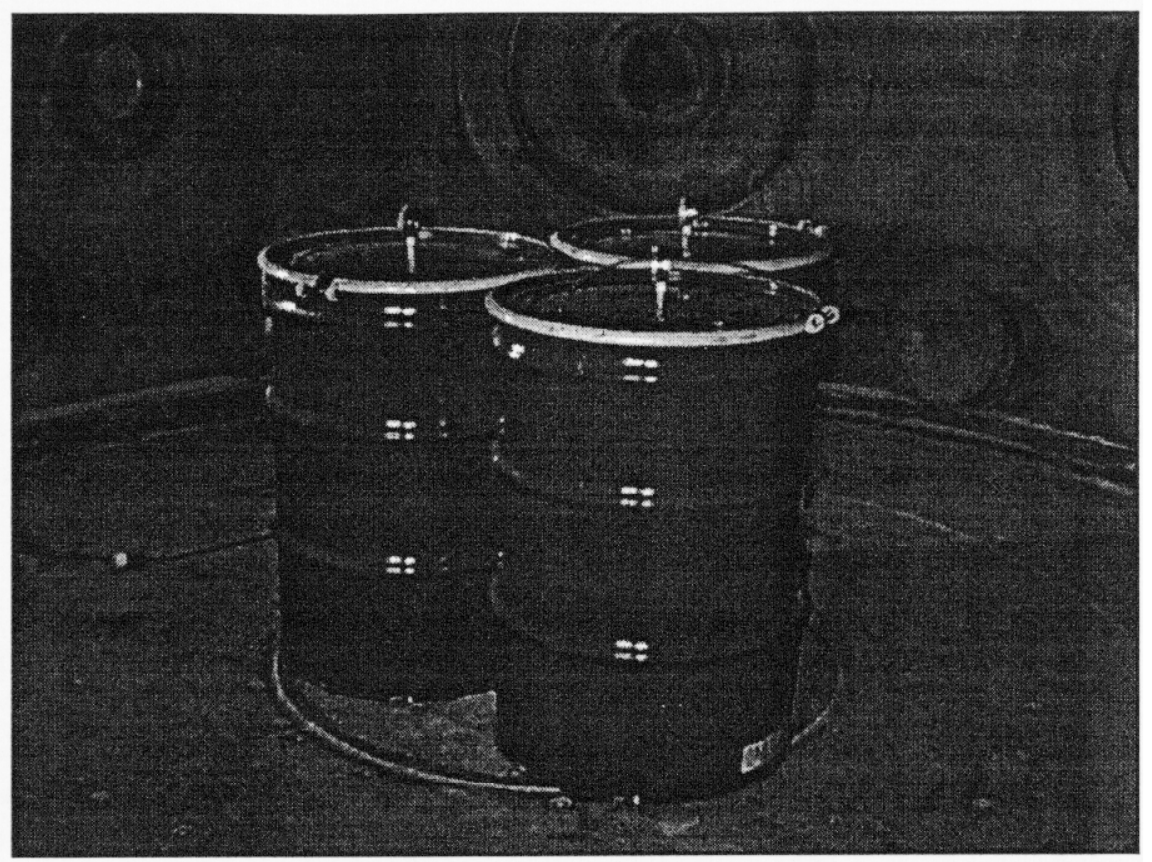

Figure C-2. The barrels shown in Figure D-1 after firing the detonator \& booster pellet. They are undisturbed.

\section{Series 6(c) - External Fire test}

As explained in the main text, we ran the 6(c) test only on mixtures of PETN and clay. Since this explosive is more sensitive than the others listed in Appendix C, we qualify the others by analogy as having passed this test. Surrogate waste containing 4 weight percent PETN was packaged as described in Section 5, above, with one exception: the surrogate waste was placed atop a one-inch layer of clay at the bottom of the barrel, instead of being in the middle of the barrel. This was required to heat the surrogate waste sufficiently to decompose the PETN." A gas-fired burner was placed beneath each drum. Several thermocouples were embedded in each sample, at different locations, to monitor the heating from the fire.

We tested three drums containing the surrogate waste. The drums were heated until the center of the surrogate waste rose above $200^{\circ} \mathrm{C}$, hot enough to decompose all the PETN. The drums showed no external disruption or distortion, there was no flame except for that from the burners, and no hazardous effects were observed. The residue remaining in the barrel showed no disruption, indicating that the PETN had gradually decomposed without any violence or production of hazardous effects. Therefore this

\footnotetext{
- Material placed at the center of the barrel did not heat significantly above $100^{\circ} \mathrm{C}$ after many hours of exposure to the gas-fired heaters - the clay is a good thermal barrier. Therefore, the test as we ran it was a severe overtest of the thermal response of the material as it will be packaged for shipment.
} 
mixture passes the 6(c) external fire test. Figure C-3 shows the initial experimental setup at Site 300 , and Figure C-4 shows the temperature histories at the center of each sample of surrogate waste.

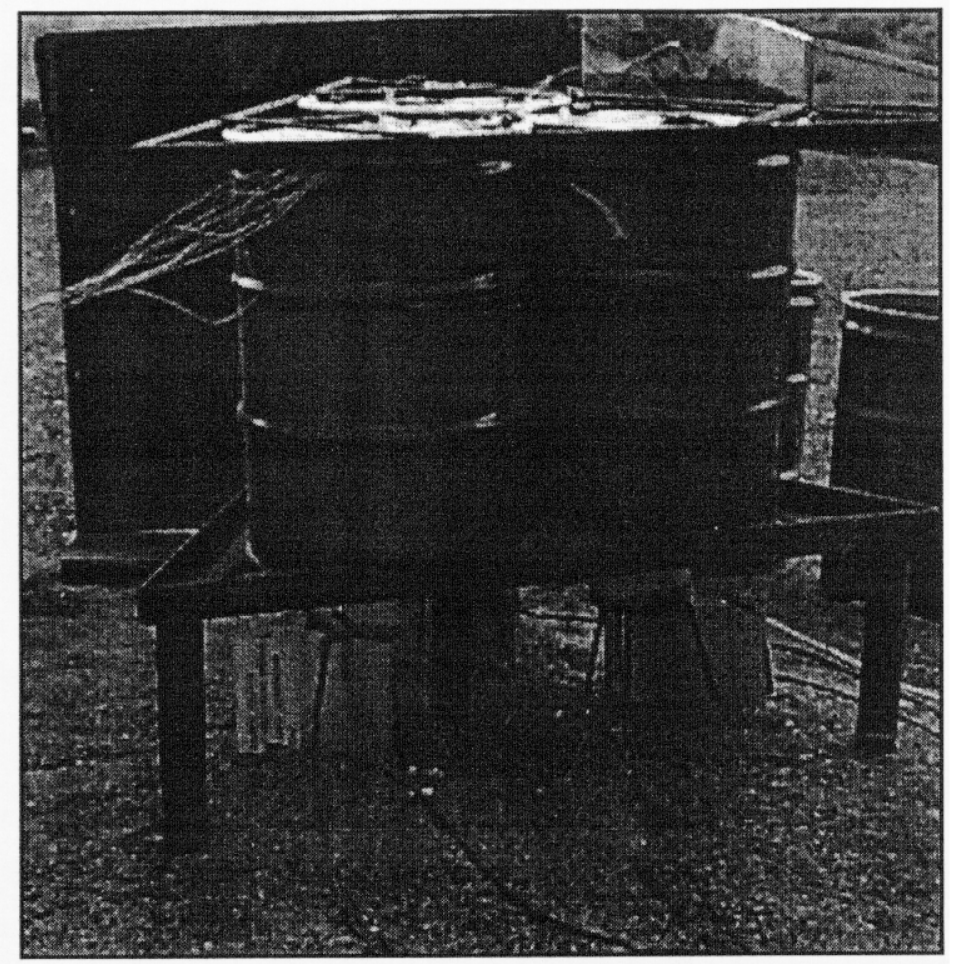

Figure C-3. Three barrels containing surrogate waste, set up for the 6(c) external fire test. The gas-fueled burners are seen below the framework supporting the barrels. The wires leading out the left side are for the thermocouples embedded in the samples. 


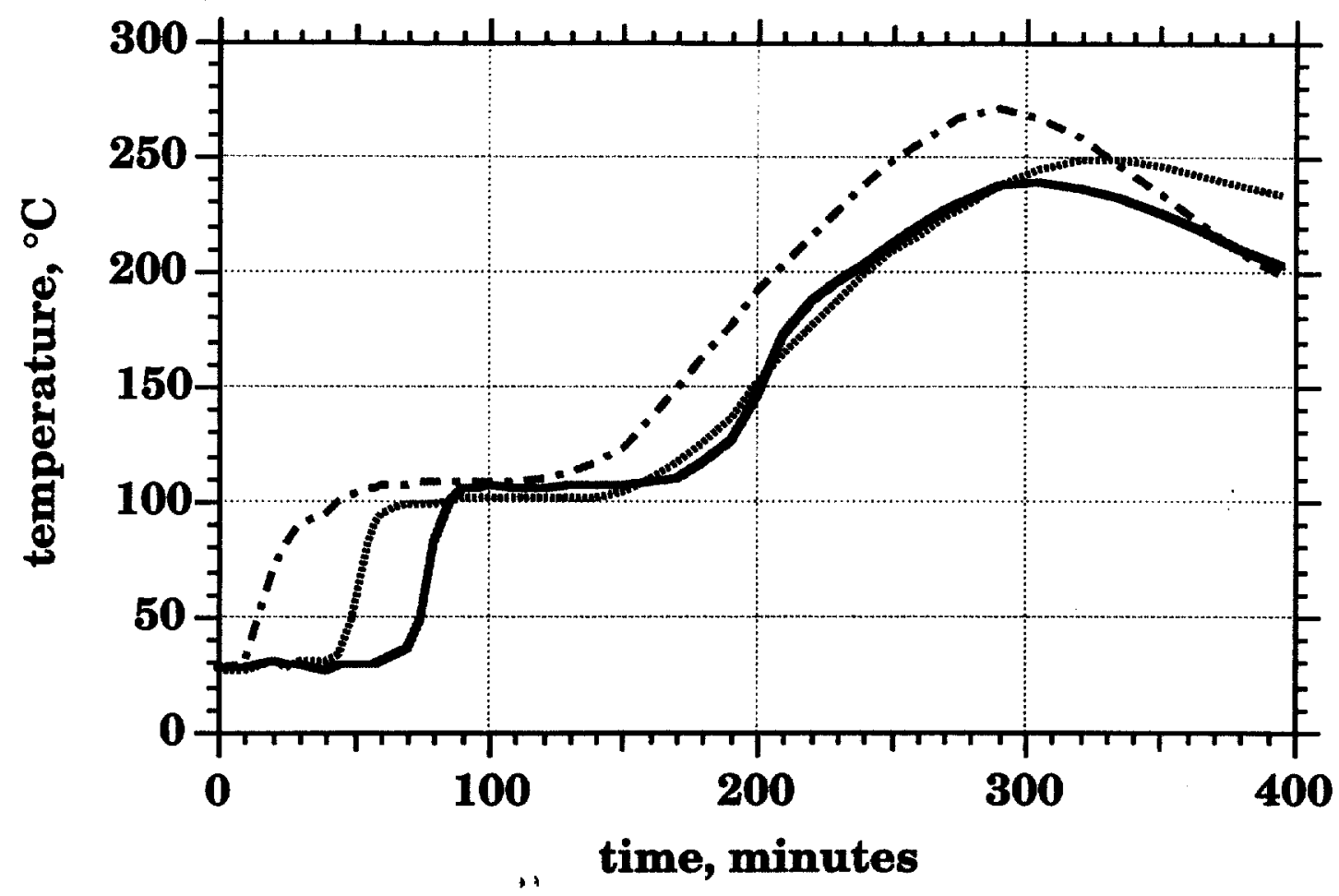

Figure C-4. Temperature profiles from the 6(c) tests shown in Figure C-3. Each line is the temperature at the center of the surrogate waste in one barrel. All three show a leveling off at $100^{\circ} \mathrm{C}$, resulting from evaporation of adsorbed water, followed by a rise to $240-270^{\circ} \mathrm{C}$. These final temperatures are sufficient to completely decompose PETN.

\section{References}

C-1. L.G. Green, R.G. Garza, J.L. Maienschein, C. Pruneda, "Testing of Explosives Mixed with Clay to Determine Maximum Explosive Content of Non-Reactive Mixtures," Lawrence Livermore National Laboratory (in preparation).

C-2. D.W. Prokosch, F. Garcia, "Chemical Reactivity Test for Thermal Stability," UCRL-JC-117941, Lawrence Livermore National Laboratory (July 1994). 


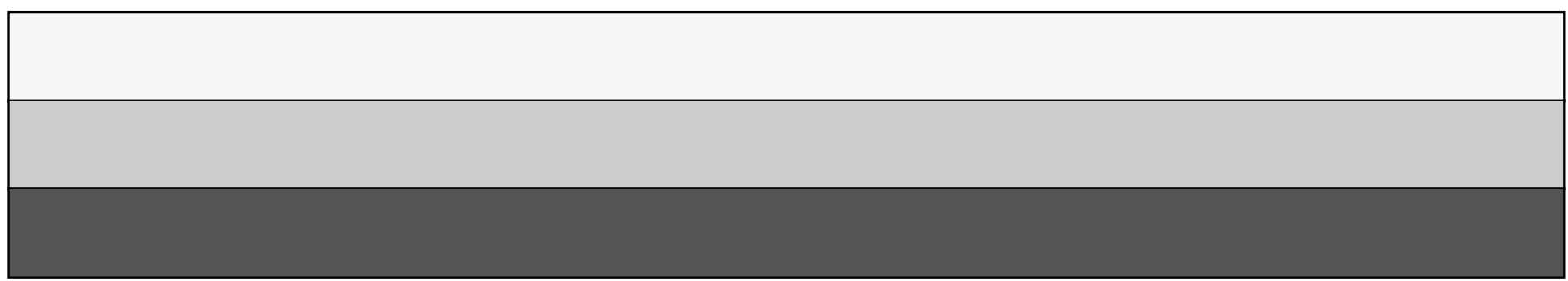

